\title{
Indium(III)-Promoted Organocatalytic Enantioselective $\alpha$-Alkylation of Aldehydes with Benzylic and Benzhydrylic Alcohols
}

\author{
Montse Guiteras Capdevila, ${ }^{[a]}$ Enrico Emer, ${ }^{[a]}$ Fides Benfatti ${ }^{[b]}$ Andrea Gualandi, ${ }^{[a]}$ \\ Claire M. Wilson, ${ }^{[\mathrm{c}]}$ and Pier Giorgio Cozzi*[a]
}

The development of novel synthetic methods for the rapid and stereoselective preparation of complex molecular scaffolds constitutes the driving force behind organic synthesis. ${ }^{[1]}$ In the past decade, organocatalytic ${ }^{[2]}$ methods have emerged as complementary to organometallic-based techniques for catalysed transformations. In particular, enamine ${ }^{[3]}$ iminium, ${ }^{[4]}$ and SOMO catalysis, ${ }^{[5]}$ as well as photocatalysis $^{[6]}$ have contributed to the enhanced synthetic utility and versatility of carbonyl compounds. The stereoselective alkylation of carbonyl groups (aldehydes and ketones) has been achieved through conceptually different activation modes. ${ }^{[7]}$

Recently, we introduced the concept of enantioselective $\mathrm{S}_{\mathrm{N}} 1$-type alkylations to organocatalysis, ${ }^{[8,9]}$ and also established the compatibility of indium(III) Lewis acids with organocatalytic processes mediated by the MacMillan catalyst. ${ }^{[10,11]}$ The compatibility of indium(III) salts in these processes creates the possibility of using carbocations that cannot be generated in the presence of Brønsted acids. ${ }^{[12]}$ The stability of the carbocation involved in the process is the primary driving force for these $\mathrm{S}_{\mathrm{N}} 1$-type reactions, and their use can be easily rationalized by the work of Mayr et al. ${ }^{[13]}$ In the presence of $\mathrm{InBr}_{3}$, allylic alcohols can provide straightforward access to alkylated aldehydes without the use of palladium or iridium salts. ${ }^{[14]}$ Herein, we report an extension to the scope of our methods to include benzylic and benzhydrylic alcohols, substrates which give access to useful intermediates for the synthesis of biologically active enantioenriched diarylethane products. ${ }^{[15]}$ This structural

[a] Dr. M. Guiteras Capdevila, Dr. E. Emer, Dr. A. Gualandi, Prof. P. G. Cozzi

Departmento di Chimica "G. Ciamician"

ALMA MATER STUDIORUM Università di Bologna

Via Selmi 2, 40126 Bologna (Italy)

Fax: (+39) 051-2099456

E-mail: piergiorgio.cozzi@unibo.it

[b] Dr. F. Benfatti

Ecole Polytech Fed Lausanne, SB, ISIC, LCBIM

CH-1015 Lausanne (Switzerland)

[c] C. M. Wilson

Centre for Synthesis and Chemical Biology School of Chemistry and Chemical Biology University College Dublin, Dublin 4 (Ireland)

Supporting information for this article is available on the WWW under http://dx.doi.org/10.1002/ajoc.201200013. motif has a diverse range of biological properties that include anticancer, antidepressant, and antiviral activity. ${ }^{[16]}$

We envisioned the direct synthesis of enantioenriched diarylethanes from readily available racemic diarylmethanols (Table 1). We have established a correlation between the electrophilicity $(E)$ of the carbenium ion employed in our $\mathrm{S}_{\mathrm{N}} 1$-type reaction and the possibility of generating such an ion. Alcohols that form carbenium ions located at -1 or above on the Mayr scale are not reactive with the enamine that is formed in situ with the MacMillan catalyst. ${ }^{[17]}$ Even in the presence of strong acids, the carbenium ions are not formed or are intercepted by water. Alternatively, by using indium(III) salts (triflate or bromide), the corresponding carbenium ion can be generated from the alcohols and intercepted by the enamine formed in situ with the MacMillan catalyst. $^{[10-11]}$ The compatibility of indium(III) salts with water, the amine, and an excess of aldehyde is the motivation for investigating this chemistry.

The reactions of model substrates $\mathbf{2}$ a-c were investigated in the presence of different Lewis acids and under various conditions. The 4-MeO derivative 2 a was rather unreactive and afforded the desired product in $75 \%$ yield as a 1:1 diastereomeric mixture in 76 and $59 \%$ ee after $24 \mathrm{~h}$, with $\mathrm{InBr}_{3}$ as the Lewis acid in $\mathrm{CH}_{2} \mathrm{Cl}_{2}$ (Table 1, entry 1). Many other benzhydrylic derivatives bearing the methoxy substituent were tested, but the reactions gave poor results. In our preceding publications we have established that steric hindrance of the incoming carbenium ion controls the stereoselectivity of the reaction. ${ }^{[1]}$ Therefore, to increase the stereoselectivity and reactivity, derivatives $\mathbf{2 b}$ and $\mathbf{2 c}$ were tested. The reaction conditions were carefully optimized by varying the solvent, Lewis acid, and MacMillan catalyst used in the reaction. Substrate 2c is more sterically demanding because of the diphenyl substituent. The introduction of an ortho substituent results in more steric hindrance in the carbenium ion, which in turn introduces a steric bias for the enamine that is formed in situ with the MacMillan catalyst. In general, different Brønsted or Lewis acids are able to promote the formation of the corresponding carbenium ion and are compatible with secondary amines and excess aldehydes. However, only $\operatorname{In}(\mathrm{OTf})_{3}$ ensured high stereoselectivity in this reaction. By varying the solvent excellent stereoselectivity was obtained with catalyst $\mathbf{3 b}$. Different benzhydrylic substituents were then tested and the data obtained are shown in Table 2. The diastereoselectivity is 
Table 1. Optimisation of reaction conditions.
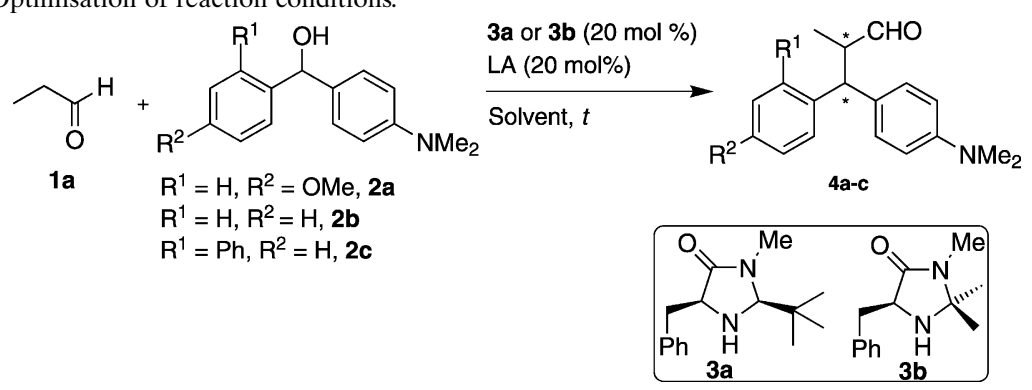

\begin{tabular}{|c|c|c|c|c|c|c|c|c|}
\hline Entry $^{[\mathrm{a}]}$ & $\mathrm{LA}^{[\mathrm{b}]}$ & Catalyst & 2 & Solvent & Yield $[\%]^{[\mathrm{c}]}$ & $\mathrm{dr}^{[\mathrm{d}]}$ & $\begin{array}{l}e e[\%]^{[\mathrm{e}]} \\
(\mathrm{M})\end{array}$ & $\begin{array}{l}e e[\%]^{[\mathrm{e}]} \\
(\mathrm{m})\end{array}$ \\
\hline $1^{[\mathrm{f}]}$ & $\mathrm{InBr}_{3}$ & $3 \mathbf{a}$ & $2 \mathbf{a}$ & $\mathrm{CH}_{2} \mathrm{Cl}_{2}$ & 75 & $1: 1$ & 76 & 59 \\
\hline 2 & $\mathrm{InBr}_{3}$ & $3 \mathbf{a}$ & $2 \mathbf{b}$ & $\mathrm{CH}_{2} \mathrm{Cl}_{2}$ & 88 & {$[\mathrm{~g}]$} & 81 & 34 \\
\hline 3 & $\mathrm{InBr}_{3}$ & $3 \mathbf{a}$ & $2 \mathrm{c}$ & $\mathrm{CH}_{2} \mathrm{Cl}_{2}$ & 73 & $3: 1$ & 78 & 35 \\
\hline 4 & $\operatorname{In}(\mathrm{OTf})_{3}$ & $3 \mathbf{a}$ & $2 \mathrm{c}$ & $\mathrm{CH}_{2} \mathrm{Cl}_{2}$ & 80 & $5: 1$ & 79 & 36 \\
\hline 5 & $\mathrm{Bi}(\mathrm{OTf})_{3}$ & $3 \mathbf{a}$ & $2 c$ & $\mathrm{CH}_{2} \mathrm{Cl}_{2}$ & 75 & $4: 1$ & 70 & 26 \\
\hline 6 & $\mathrm{InCl}_{3}$ & $3 \mathbf{a}$ & $2 \mathrm{c}$ & $\mathrm{CH}_{2} \mathrm{Cl}_{2}$ & 75 & $3: 1$ & 79 & 40 \\
\hline 7 & $p$-TSA & $3 \mathbf{a}$ & $2 \mathrm{c}$ & $\mathrm{CH}_{2} \mathrm{Cl}_{2}$ & 60 & $4: 1$ & 50 & 50 \\
\hline 8 & $\operatorname{In}(\mathrm{OTf})_{3}$ & $3 \mathbf{b}$ & $2 \mathrm{c}$ & $\mathrm{CH}_{2} \mathrm{Cl}_{2}$ & 80 & $7: 1$ & 98 & 56 \\
\hline 9 & $\operatorname{In}(\mathrm{OTf})_{3}$ & $3 \mathbf{b}$ & $2 \mathrm{c}$ & $\mathrm{CH}_{3} \mathrm{CN}$ & 50 & $3: 1$ & 97 & 42 \\
\hline 10 & $\operatorname{In}\left(\mathrm{OTf}_{3}\right)_{3}$ & 3b & $2 \mathrm{c}$ & $n$-hexane & 80 & $5: 1$ & 99 & 85 \\
\hline 11 & $\operatorname{In}(\text { OTf })_{3}$ & $\mathbf{3 b}$ & $2 b$ & $n$-hexane & 78 & $L^{[g]}$ & 98 & 96 \\
\hline
\end{tabular}

[a] All the reactions were performed with alcohol (1 equiv) and aldehyde (3 equiv) until completion (as judged by TLC). [b] The acid catalyst was added to the reaction mixture after the addition of the MacMillan catalyst. [c] Yield of isolated product after chromatographic purification. [d] The dr (anti/syn) was determined from the crude reaction mixture by ${ }^{1} \mathrm{H}$ NMR spectroscopy. [e] $e e$ values were determined by HPLC on a chiral stationary phase (see Supporting Information for details). [f] The reaction was conducted at RT for $24 \mathrm{~h}$ [g] Not determined by ${ }^{1} \mathrm{H}$ NMR spectroscopy. LA = Lewis acid; $\mathrm{M}=$ major isomer; $\mathrm{m}=$ minor isomer; $\mathrm{n} . \mathrm{d}$.= not determined; $\mathrm{TSA}=$ toluenesulfonic acid $\mathrm{Tf}=$ trifluoromethanesulfonate.

dependent on the ortho-substituent of the $\mathrm{R}^{3}$ aryl group. The absence of an ortho substituent (Table 2, entries 1-3) or the use of a less sterically hindered group, such as benzyloxy or methoxy (Table 2, entries 6-9), considerably lowers the stereoselectivity of the reaction. The presence of a $\mathrm{NMe}_{2}$ group as the $\mathrm{R}^{2}$ substituent influences the yield and the rate of the reaction. In general, when more hindered aldehydes such as octanal are used, the diastereomeric ratio (dr) of the reaction is lowered. Heteroaromatic substituents are tolerated, although a moderate $\mathrm{dr}$ was obtained with $\mathrm{R}^{3}=$ thiophene (Table 2, entries 10-12). Unfortunately alkyl substituents, such as an 4-methyl, were not suitable for the reaction.

As the substitution of the aryl groups is essential, we investigated if $4-\mathrm{NMe}_{2} \mathrm{Ph}$ alone was enough to stabilize the carbenium ion and allow access to the corresponding carbenium ion from the benzylic substituents. As previously discussed, benzylic alcohols form carbenium ions with $E=6$ on the electrophilicity scale and because of their reactivity the carbenium ions are not accessible if they are generated in the presence of water. To our delight, the reaction of benzylic substrates bearing an activating $4-\mathrm{NMe}_{2}$ group in the para position was possible and optimization of the reaction conditions is shown in Table 3. However, the reaction of benzylic substituents was difficult because the benzyl alcohols tend to undergo elimination to form the corresponding alkene 6. As the reactivity of the carbenium ion is greater than the nucleophilicity of the alcohol, there is a competitive reaction with the enamine that is formed in situ. Changing the solvent from $n$-hexane or the addition of different Lewis acids did not improve the yield and resulted in formation of the elimination product.

Forcing reaction conditions gave lower yields because of the formation of an ether by reaction of the alcohol and the carbenium ion. The use of $n$-hexane was found to be important to minimize the formation of the alkene (Table 3, entry 10). Performing the reaction at $0^{\circ} \mathrm{C}$ gave the highest yield of the desired product without formation of any elimination product (Table 3 , entry 11). The use of catalyst 3b gave high $e e$ values ( $98 \%$ and $94 \%$ for the two diastereoisomers) but the maximum $\mathrm{dr}$ was moderate at $2: 1$. When 3c was used under the optimized conditions, the $e e$ values remained the same but the $\mathrm{dr}$ increased to $4.5: 1$. A number of substituted benzylic substrates were then selected and treated with aldehydes $\mathbf{1 a}$ and $\mathbf{1 b}$ in the presence of the MacMillan catalysts $\mathbf{3 b}$ and $\mathbf{c}$. The desired substrates were obtained by reaction of $4-\mathrm{Me}_{2} \mathrm{NPhCHO}$ with lithiated alkynes $\mathbf{7 l}$ and $\mathbf{7 n}$ (see the Supporting Information for details). The yields of the corresponding alcohols were good, and the alcohols were then hydrogenated with $\mathrm{Pd} / \mathrm{C}$ as the catalyst. The reaction was capricious, as complete hydrogenation of the benzylic alcohols was not consistently achieved. The quality of the palladium catalyst was crucial to obtain a good yield for the desired transformation.

The reduction needed to be monitored carefully to avoid long reaction times. The reduction gave moderate to low yields of adducts $2 \mathbf{l}$ and $\mathbf{2 n}$, which were used in the addition of the aldehydes $\mathbf{1 a}$ and $\mathbf{1 b}$ (Table 4). Whereas catalyst 3b gave excellent stereoselectivity, better drs were guaranteed in the case of the aldehyde $\mathbf{1 a}$ by using $\mathbf{3 c}$. When the more hindered aldehyde $\mathbf{1} \mathbf{b}$ was used with various functionalized substrates and catalyst $\mathbf{3} \mathbf{b}$, better drs were obtained. The compatibility of indium with a wide range of functional groups is illustrated by the use of substrates $\mathbf{2} \mathbf{h}-\mathbf{n}$. The presence of functional groups, such as esters and amides, as well as protected amines and alcohols, is well tolerated. Good drs and excellent $e e$ values were obtained in the reactions. The absolute configuration of the product was established for the benzhydrylic and benzylic substrates. In our 
Table 2. Organocatalytic alkylation of aldehydes $\mathbf{1}$ with alcohols $\mathbf{2}$.

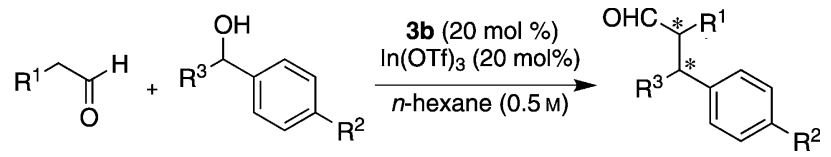

$\mathrm{R}^{1}=\mathrm{Me}, \mathbf{1 a} \quad \mathrm{R}^{2}=\mathrm{NMe}_{2}, \mathrm{R}^{3}=$ 4-methoxyphenyl, 2a $\quad \mathrm{R}^{1}=\mathrm{Me}, \mathbf{4 a - g}$

$R^{1}=\mathrm{C}_{6} \mathrm{H}_{13}, \mathbf{1 b} \mathrm{R}^{2}=\mathrm{NMe}_{2}, \mathrm{R}^{3}=$ phenyl $, \mathbf{2 b} \quad \mathrm{R}^{1}=\mathrm{C}_{6} \mathrm{H}_{13}, \mathbf{5 b}$-f

$\mathrm{R}^{2}=\mathrm{NMe}_{2}, \mathrm{R}^{3}=2$-diphenyl, $2 \mathrm{c}$

$\mathrm{R}^{2}=\mathrm{NMe}_{2}, \mathrm{R}^{3}=$ 2-methoxyphenyl, 2d

$\mathrm{R}^{2}=\mathrm{NMe}_{2}, \mathrm{R}^{3}=2$-(benzyloxy)phenyl, $2 \mathrm{e}$

$\mathrm{R}^{2}=\mathrm{NMe}_{2}, \mathrm{R}^{3}=$ 3-thiophenyl, $2 \mathrm{f}$

$\mathrm{R}^{2}=\mathrm{OMe}, \mathrm{R}^{3}=$ 2-thiophenyl, $\mathbf{2 g}$

\begin{tabular}{lllllll}
\hline Entry $^{[\mathrm{a}]}$ & $\mathbf{1}$ & $\mathbf{2}$ & Yield $^{[\mathrm{b}]}$ & $\mathrm{dr}^{[\mathrm{c}]}$ & $\begin{array}{l}e e[\%] \\
(\mathbf{M})^{[\mathrm{d}]}\end{array}$ & $\begin{array}{l}e e[\%] \\
(\mathrm{m})^{[\mathrm{d}]}\end{array}$ \\
\hline 1 & $\mathbf{1 a}$ & $\mathbf{2 a}$ & 85 & $2: 1$ & $95^{[\mathrm{e}]}$ & $92^{[\mathrm{e}]}$ \\
2 & $\mathbf{1 a}$ & $\mathbf{2 b}$ & 80 & $2: 1$ & 98 & 96 \\
3 & $\mathbf{1 b}$ & $\mathbf{2 b}$ & 85 & $2: 1$ & 89 & 81 \\
4 & $\mathbf{1 a}$ & $\mathbf{2 c}$ & 90 & $5: 1$ & 99 & 83 \\
5 & $\mathbf{1 b}$ & $\mathbf{2 c}$ & 66 & $3: 1$ & 93 & 71 \\
6 & $\mathbf{1 a}$ & $\mathbf{2 d}$ & 70 & $2: 1$ & 98 & 91 \\
7 & $\mathbf{1 b}$ & $\mathbf{2 d}$ & 86 & $1: 1$ & 90 & 88 \\
8 & $\mathbf{1 a}$ & $\mathbf{2 e}$ & 60 & $1: 1$ & 94 & 95 \\
9 & $\mathbf{1 b}$ & $\mathbf{2 e}$ & 79 & $1: 1$ & 90 & 81 \\
10 & $\mathbf{1 a}$ & $\mathbf{2 f}$ & 84 & $2: 1$ & 93 & 90 \\
11 & $\mathbf{1 b}$ & $\mathbf{2 f}$ & 70 & $1.5: 1$ & 88 & 80 \\
12 & $\mathbf{1 a}$ & $\mathbf{2 g}$ & 88 & $1.1: 1$ & $88^{[\mathrm{e}]}$ & $86^{[\mathrm{e}]}$ \\
\hline
\end{tabular}

[a] All the reactions were performed with alcohol (1 equiv) and aldehyde ( 3 equiv) for $24 \mathrm{~h}$. [b] Yield of isolated product after chromatographic purification. [c] The dr (anti/syn) was determined from the crude reaction mixture by ${ }^{1} \mathrm{H}$ NMR spectroscopy. [d] ee values were determined by HPLC on a chiral stationary phase (see Supporting Information for details). [e] ee value was determined for the corresponding alcohol.

previous studies, we suggested a model for the stereoselective induction; it is believed that this model was followed in all cases that we have described in the present study. On the basis of this model and starting with the $S$-MacMillan catalyst, we expected formation of the $R$-configured stereocentre at the $\alpha$ position of the aldehydes. The absolute and relative configurations of the benzylic substrates were assigned by comparison of the HPLC traces with the product 4g. The absolute configuration of the $\mathrm{C} 2$ stereocentre was confirmed by diastereoselective addition of the titanium enolate derivative of chiral oxazolidinone $\mathbf{8}$ (Scheme 1 ) $^{[18]}$ The $\mathrm{S}_{\mathrm{N}} 1$-type reaction of the titanium enolate was described by Evans et al. in their seminal paper. On this basis, we treated alcohol $\mathbf{2} \mathbf{g}$ with the titanium enolate of $\mathbf{8}$. The presence of titanium chloride in the reaction mixture guarantees the formation of the carbenium ion, which is attacked by the oxazolidinone in a stereoselective manner (see the Supporting Information). The oxazolidinone derivative 9 (obtained in $60 \%$ yield) was reduced to the corresponding alcohol $\mathbf{4} \mathbf{g}$ by Super-Hydride. The configuration of the stereocentre at the $\alpha$ position to the aldehyde was established by comparison of the HPLC traces of product $\mathbf{4 g}$ to the corresponding alcohol. The relative configurations (at the C3 position) of the two diastereoisomers of $\mathbf{4} \mathbf{g}$ obtained were assigned on the basis of the work published by Stadler and Bach on the diastereoselective addition of a nucleophile
Table 3. Optimisation of reaction conditions for the addition of $\mathbf{1}$ a to $2 \mathbf{h}$.

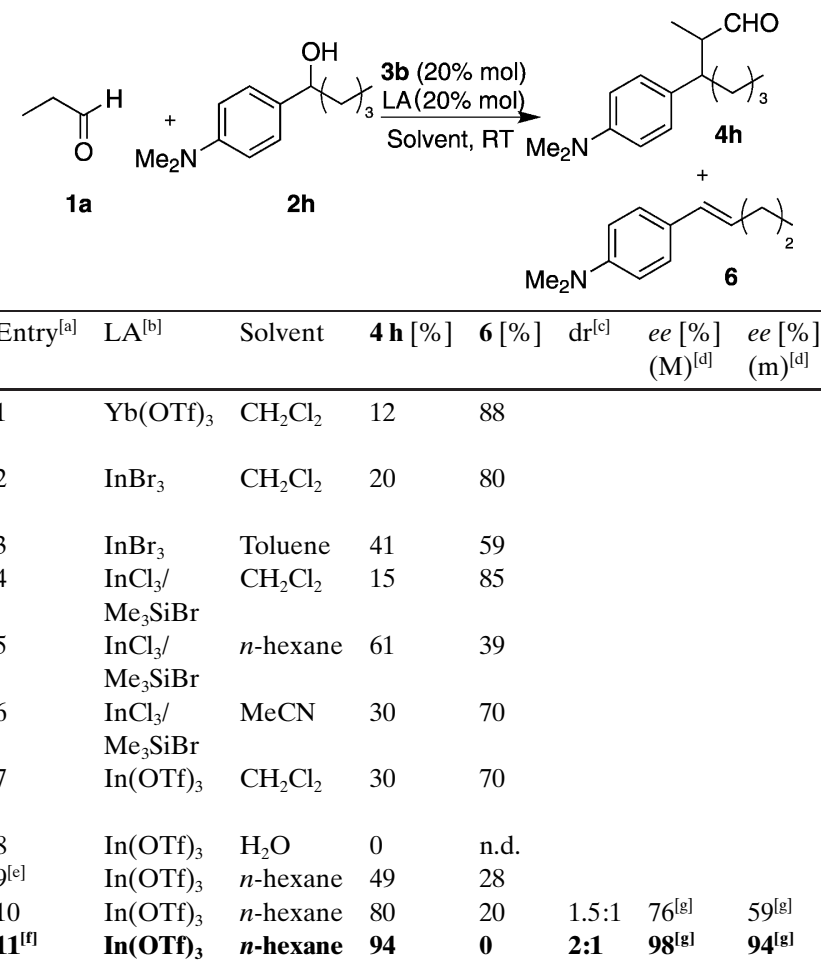

[a] All the reactions were performed with alcohol (1 equiv) and aldehyde (3 equiv) until completion (as judged by TLC). [b] The acid catalyst was added to the reaction mixture after the addition of the MacMillan catalyst. [c] The $\mathrm{dr}$ (anti/syn) was determined from the crude reaction mixture by ${ }^{1} \mathrm{H}$ NMR spectroscopy. [d] $e e$ values were determined by HPLC on a chiral stationary phase (see Supporting Information for details). [e] The MacMillan catalyst was added in two portions in the first $2 \mathrm{~h}\left(10 \mathrm{~mol} \%\right.$ each). [f] The reaction was conducted at $0{ }^{\circ} \mathrm{C}$ until completion (as judged by TLC). [g] ee value was determined for the corresponding alcohol.

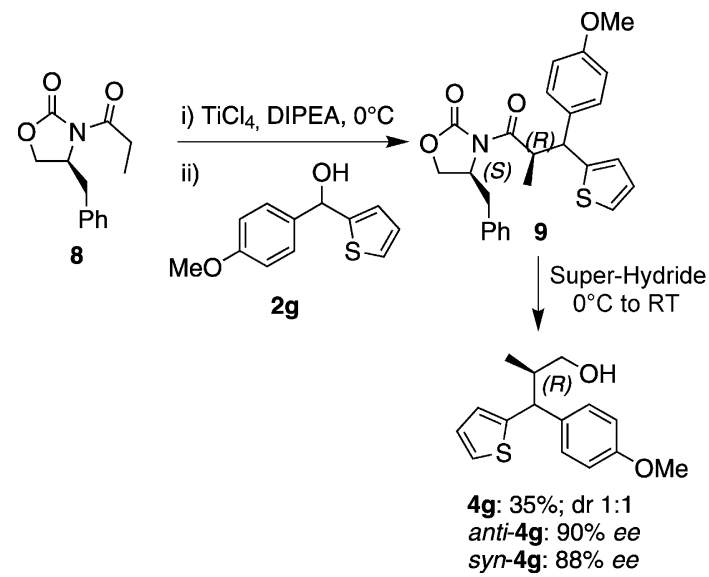

Scheme 1. Determination of the absolute configuration of $\mathbf{4} \mathbf{g}$.

to a carbanion. ${ }^{[19]}$ Stadler and Bach determined the syn/anti configuration of benzylic substrates obtained by $\mathrm{S}_{\mathrm{N}} 1$-type Friedel-Crafts reactions. ${ }^{1} \mathrm{H}$ NMR coupling constants ${ }^{3} J_{\mathrm{H}, \mathrm{H}}$ in the range $9.5-11.5 \mathrm{~Hz}$ for $\mathrm{H} 2$ and $\mathrm{H} 3$ of the 1,1-diarylsubstituted products indicate an antiperiplanar orientation of the two protons in the major conformer. 
Table 4. Optimisation of reaction conditions for the addition of aldehydes $\mathbf{1}$ to alcohols $\mathbf{2}$.

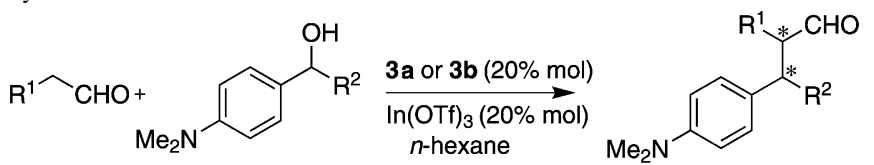

$$
\mathrm{R}^{1}=\mathrm{Me}, \mathbf{1 a} \quad \mathrm{R}^{2}=n \mathrm{Bu}, \mathbf{2 h}
$$$$
\mathbf{R}^{1}=\mathrm{C}_{6} \mathrm{H}_{13}, \mathbf{1 b} \mathbf{R}^{2}=\mathrm{Et}, \mathbf{2 i}
$$$$
\mathrm{R}^{2}=\mathrm{CH}_{2} \mathrm{C}_{6} \mathrm{H}_{11}, \mathbf{2 j}
$$$$
\mathrm{R}^{2}=\mathrm{CH}_{2} \mathrm{CH}_{2} \mathrm{OSiMe}_{2} \mathrm{tBu}, \mathbf{2 k}
$$$$
\mathrm{R}^{2}=\mathrm{CH}_{2} \mathrm{CH}_{2} \mathrm{COOEt} \text {, } 2 \text { I }
$$$$
\mathrm{R}^{2}=\mathrm{CH}_{2} \mathrm{CH}_{2} \mathrm{CONH}_{2}, 2 \mathrm{~m}
$$$$
\mathrm{R}^{2}=\mathrm{CH}_{2} \mathrm{CH}_{2} \mathrm{CH}_{2} \mathrm{NPhBoc}, 2 \mathrm{n}
$$

$$
R^{1}=M e, 4 h, 4 j-n
$$

$\mathbf{R}^{1}=\mathrm{C}_{6} \mathrm{H}_{13}, \mathbf{5 h}, \mathbf{5 i}, \mathbf{5 k}, \mathbf{5 l}, \mathbf{5 n}$

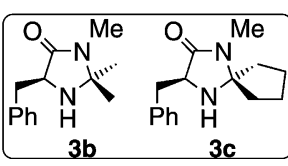

\begin{tabular}{llllllll}
\hline Entry $^{[\mathrm{a}]}$ & Catalyst & $\mathbf{2}$ & Product & Yield $^{[\mathrm{b}]}$ & $\mathrm{dr}^{[\mathrm{c}]}$ & $\begin{array}{l}e e[\%] \\
(\mathrm{M})^{[\mathrm{d}]}\end{array}$ & $\begin{array}{l}e e[\%] \\
(\mathrm{m})^{[\mathrm{d}]}\end{array}$ \\
\hline 1 & $\mathbf{3 c}$ & $\mathbf{2 h}$ & $\mathbf{4 h}$ & 94 & $4.5: 1$ & $98^{[\mathrm{e}]}$ & $90^{[\mathrm{e}]}$ \\
2 & $\mathbf{3 b}$ & $\mathbf{2 h}$ & $\mathbf{5 h}$ & 94 & $2: 1$ & $92^{[\mathrm{e}]}$ & $86^{[\mathrm{e}]}$ \\
3 & $\mathbf{3 b}$ & $\mathbf{2 i}$ & $\mathbf{5 i}$ & 90 & $3: 1$ & $76^{[\mathrm{e}]}$ & $94^{[\mathrm{e}]}$ \\
4 & $\mathbf{3 c}$ & $\mathbf{2 j}$ & $\mathbf{4 j}$ & 88 & $5: 1$ & $92^{[\mathrm{e}]}$ & $86^{[\mathrm{e}]}$ \\
5 & $\mathbf{3 c}$ & $\mathbf{2 k}$ & $\mathbf{4 k}$ & 85 & $6: 1$ & 99 & 86 \\
6 & $\mathbf{3 b}$ & $\mathbf{2 k}$ & $\mathbf{5 k}$ & 60 & $3: 1$ & 96 & 92 \\
7 & $\mathbf{3 c}$ & $\mathbf{2}$ & $\mathbf{4 1}$ & 45 & $6: 1$ & 97 & 82 \\
8 & $\mathbf{3 b}$ & $\mathbf{2}$ & $\mathbf{5 1}$ & 60 & $2.5: 1$ & 96 & 91 \\
9 & $\mathbf{3 b}$ & $\mathbf{2 m}$ & $\mathbf{4 m}$ & 88 & $5.5: 1$ & $90^{[\mathrm{f}]}$ & $71^{[\mathrm{f}]}$ \\
10 & $\mathbf{3 c}$ & $\mathbf{2 n}$ & $\mathbf{4 n}$ & 92 & $4.5: 1$ & 95 & 97 \\
11 & $\mathbf{3 b}$ & $\mathbf{2 n}$ & $\mathbf{5 n}$ & 75 & $2.5: 1$ & 96 & 91 \\
\hline
\end{tabular}

[a] All the reactions were performed with alcohol (1 equiv) and aldehyde (3 equiv) until completion (as judged by TLC). [b] Yield of isolated product after chromatographic purification. [c] The $\mathrm{dr}$ (anti/syn) was measured from the crude reaction mixture by ${ }^{1} \mathrm{H}$ NMR spectroscopy. [d] $e e$ values were determined by HPLC on a chiral stationary phase (see Supporting Information for details). [e] ee value was determined for the corresponding alcohol. [f] ee value was determined for the corresponding trifluoroacetylated alcohol. Boc $=$ tert-butyloxycarbonyl.

We based our assignments on the consistent shielding and deshielding effects of the $\mathrm{C} 2$ methylene protons, which presumably originate from the ring current of the anisyl substituent. The data obtained shows that the anti diastereoisomer (for which an antiperiplanar conformation of protons $\mathrm{H} 2$ and $\mathrm{H} 3$ is deduced from their coupling constants) experiences a shielding effect for the methyl group at the $\mathrm{C} 2$ position, relative to the syn diastereoisomer (Scheme 2). The spatial proximity of the anisyl substituent to the methyl group, and the fact that the protons of the methyl group are within the ring current of the anisyl substituent, were fully supported by X-ray crystallographic evidence obtained by Stadler and Bach.

This shielding effect is also experienced by the corresponding aldehydes. By careful chromatographic separation it was possible to obtain a sample with $\mathrm{dr}=1.2: 1$ and the relative configuration of the diastereoisomers were consequently assigned for the ester and aldehyde moieties. For most of the isolated products, similar evidence was obtained by ${ }^{1} \mathrm{H}$ NMR spectroscopy; the relative configuration of the major diastereoisomer obtained in the addition of aldehydes to hindered benzhydrylic substrates was assigned as anti. The relative configurations of the esters were correlated to the corresponding aldehydes. In the case of the ad-

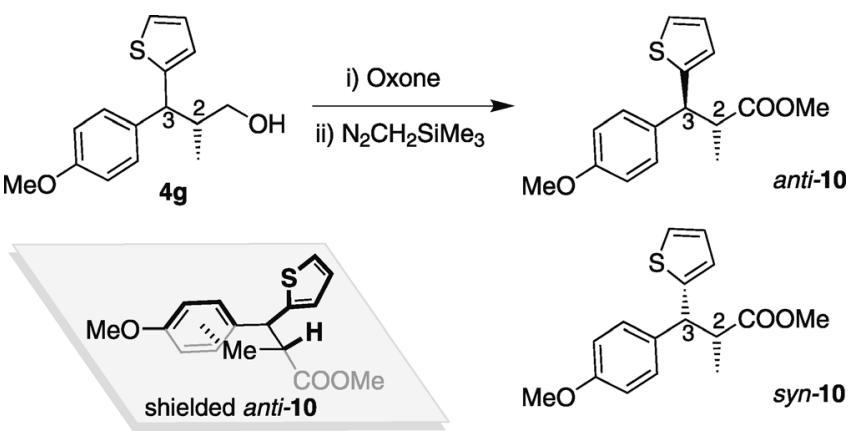

Scheme 2. Determination of the relative configurations of diastereoisomers anti-4g and syn-4g.

dition of the aldehydes to the benzylic derivatives, the absolute and relative configurations of the obtained stereoisomer were assigned by similar methods. The absolute and relative configurations of the products obtained by the addition of aldehydes to propargylic alcohols were previously established by our group. The relative and absolute configurations of the benzylic adducts were assigned by comparison of HPLC analysis of the products which was obtained from propargylic derivative $\mathbf{1 1}$ after reduction of the alkyne to the corresponding aliphatic chain (Scheme 3). ${ }^{[11 a]}$ The stereoisomer obtained in this reaction was consistent with our previously suggested model.

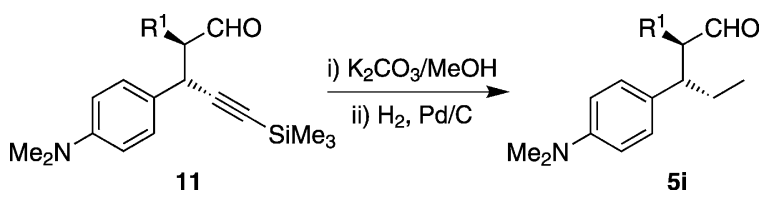

Scheme 3. Determination of the absolute configuration of $\mathbf{5 i}$.

It is noteworthy that the $\mathrm{NMe}_{2}$ group is not only an activating group capable of stabilizing the carbenium ion, it can also be advantageously used for further synthetic transformations by using $\mathrm{Ni}$ or $\mathrm{Pd}$ chemistry. ${ }^{[20]}$ After reduction and protection of the primary alcohol group with $t \mathrm{BuMe}_{2} \mathrm{SiCl}$, substrate $\mathbf{4 h}$ was transformed into the corresponding ammonium triflate by treatment with methyl triflate (Scheme 4). Subsequent treatment of the ammonium salt with $4-\mathrm{MePhMgBr}$ and $4-\mathrm{MeOPhMgBr}$ in the presence of catalytic amounts of $\left[\mathrm{PdCl}_{2}\left(\mathrm{PPh}_{3}\right)_{2}\right](5 \mathrm{~mol} \%)$ gave the desired product $13 \mathbf{a}$ and $\mathbf{1 3} \mathbf{b}$, respectively, in good yields with no racemization. This reaction shows that further functionalization of the product obtained in our reaction is possible.

In conclusion, we have enhanced the scope of organocatalytic $\mathrm{S}_{\mathrm{N}} 1$-type reactions to include benzylic and benzhydrylic substrates. High ee values and moderate drs are obtained with activated benzylic and benzhydrylic alcohols. In all examples the presence of the $4-\mathrm{NMe}_{2} \mathrm{Ph}$ group is essential for obtaining high yields in the reactions and this functional group could be useful for further chemical transfor- 


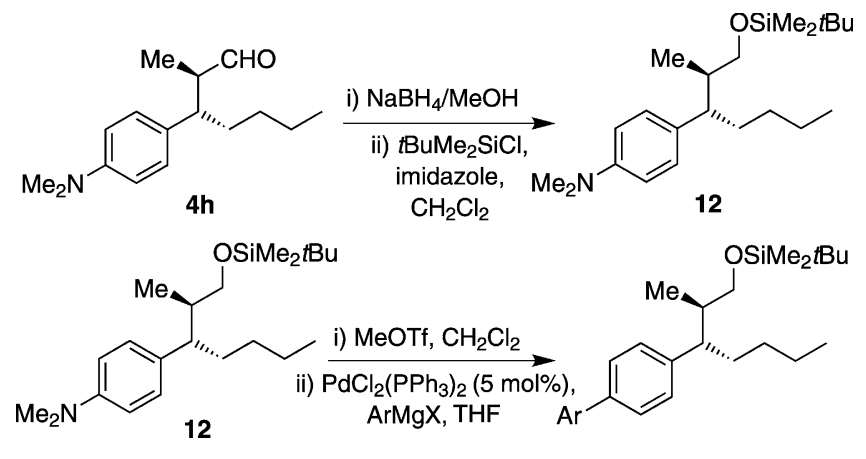

13a, $\mathrm{Ar}=4-\mathrm{MePh}, \quad 87 \%$

13a, $\mathrm{Ar}=4-\mathrm{MePh}, 87 \%$
13b, $\mathrm{Ar}=4-\mathrm{MeOPh}, 82 \%$

Scheme 4. Functionalization of dimethylamino derivatives.

mations. Benzylic substrates bearing different functional groups are also compatible with the reaction. The reactions are performed in the presence of indium(III) salts, which are crucial for the formation of the intermediate carbenium ion. The compatibility of indium salts and organocatalytic processes can also be considered for other reactions. Studies to further expand the scope of the $\mathrm{S}_{\mathrm{N}} 1$-type organocatalytic reactions to include less-stable carbenium ions and avoid the presence of strong activating groups are ongoing in our laboratory.

\section{Acknowledgements}

The European Commission through the project FP7-201431 (CATAFLU.OR) is acknowledged for financial support. The University of Bologna, MIUR, and Fondazione del Monte (Bologna) are also acknowledged for financial support. Dr. Riccardo Sinisi is acknowledged for preliminary experiments.

Keywords: alkylation $\cdot$ enamines $\cdot$ indium
organocatalysis $\cdot \mathrm{S}_{\mathrm{N}} 1$-type reactions

[1] A. Mendoza, Y. Hishihara, P. Baran, Nat. Chem. 2012, 4, 21-25.

[2] For reviews about organocatalysis, see: a) P. Melchiorre, M. Marigo, A. Carlone, G. Bartoli, Angew. Chem. 2008, 120, 62326265; Angew. Chem. Int. Ed. 2008, 47, 6138-6171; b) C. F. Barbas III, Angew. Chem. 2008, 120, 44-50; Angew. Chem. Int. Ed. 2008, 47, 42-47; c) G. Lelais, D. W. C. MacMillan, Aldrichimica Acta 2006, 39, 79-87.

[3] B. List, Acc. Chem. Res. 2004, 37, 548-557.
[4] A. Erkkilä, I. Majander, P. M. Pihko, Chem. Rev. 2007, 107, 54165470.

[5] T. D. Beeson, A. Mastracchio, J.-B. Hong, K. Ashton, D. W. C. MacMillan, Science 2007, 316, 582-585.

[6] a) D. A. Nicewicz, D. W. C. MacMillan, Science 2008, 322, 77-80; b) M. Neumann, S. Füldner, B. König, K. Zeitler, Angew. Chem. 2011, 123, 981-985; Angew. Chem. Int. Ed. 2011, 50, 951-954.

[7] D. W. C. MacMillan, Nature 2008, 455, 304-308.

[8] For $\mathrm{S}_{\mathrm{N}} 1$-type alkylation reactions, see: a) P. G. Cozzi, F. Benfatti, L. Zoli, Angew. Chem. 2009, 121, 1339-1342; Angew. Chem. Int. Ed. 2009, 48, 1313-1316; b) F. Benfatti, E. Benedetto, P. G. Cozzi, Chem. Asian J. 2010, 5, 2047-2052; c) A. R. Brown, W.-H. Kuo, E. N. Jacobsen, J. Am. Chem. Soc. 2010, 132, 9286-9288; d) L. Zhang, L. Cui, X. Li, S. Luo, J.-P. Cheng, Chem. Eur. J. 2010, 16, 2045-2049; e) G. Bergonzini, S. Vera, P. Melchiorre, Angew. Chem. 2010, 122, 9879-9882; Angew. Chem. Int. Ed. 2010, 49, 9685-9688.

[9] a) M. G. Capdevila, F. Benfatti, L. Zoli, P. G. Cozzi, Chem. Commun. 2009, 5019-5021; b) A. Gualandi, E. Emer, M. Guiteras Capdevila, P. G. Cozzi, Angew. Chem. 2011, 123, 7988-7992; Angew. Chem. Int. Ed. 2011, 50, 7842-7846; c) A. Gualandi, D. Petruzziello, E. Emer, P. G. Cozzi, Chem. Commun. 2012, 48, $3614-$ 3616.

[10] For reaction with allylic alcohols, see: M. G. Capdevila, F. Benfatti, L. Zoli, M. Stenta, P. G. Cozzi, Chem. Eur. J. 2010, 16, 1123711241.

[11] Reaction with propargylic alcohols, see: a) R. Sinisi, M. Victoria Vita, A. Gualandi, E. Emer, P. G. Cozzi, Chem. Eur. J. 2011, 17, 7404-7408; For similar studies see: b) K. Motoyama, M. Ikeda, Y. Myake, Y. Nishibayashi, Eur. J. Org. Chem. 2011, 2239-2246.

[12] E. Emer, R. Sinisi, M. Guiteras Capdevila, D. Petruzziello, F. De Vicentiis, P. G. Cozzi, Eur. J. Org. Chem. 2011, 647-666.

[13] a) H. Mayr, B. Kempf, A. R. Ofial, Acc. Chem. Res. 2003, 36, 6677; b) S. Lakhdar, B. Maji, H. Mayr, Angew. Chem. 2012, 124, 5837-5840; Angew. Chem. Int. Ed. 2012, 51, 5739-5742; c) For detailed references, see: http://www.cup.uni-muenchen.de/oc/mayr/ CDmayrres.html.

[14] Z. Lu, S. Ma, Angew. Chem. 2008, 120, 264-303; Angew. Chem. Int. Ed. 2008, 47, 258-297.

[15] B. L. H. Taylor, E. C. Swift, J. D. Waetzig, E. R. Jarvo, J. Am. Chem. Soc. 2011, 133, 389-391.

[16] a) Z. Huang, Y. Ducharme, D. MacDonald, A. Robichaud, Curr. Opin. Chem. Biol. 2001, 5, 432-438; b) A. V. Cheltsov, M. Aoyagi, A. Aleshin, E. C.-W. Yu, T. Gilliland, D. Zhai, A. A. Bobkov, J. C. Reed, R. C. Liddington, R. Abagyan, J. Med. Chem. 2010, 53, 3899-3906.

[17] Water generated by the catalytic enamine cycle is a nucleophile and could react with the carbenium ion.

[18] D. A. Evans, D. Reger, M. T. Bilodeau, F. Urpi, J. Am. Chem. Soc. 1991, 113, 1047-1049.

[19] D. Stadler, T. Bach, Chem. Asian J. 2008, 3, 272-284.

[20] a) J. T. Reeves, D. R. Fandrick, Z. Tan, J. J. Song, H. Lee, N. K. Jee, C. H. Senanayake, Org. Lett. 2010, 12, 4388-4391; b) N. Paras, B. Simmons, D. W. C. MacMillan, Tetrahedron 2009, 65, 3232-3238.

Received: April 11, 2012

Revised: June 22, 2012 Published online: July 24, 2012 